\title{
Sight and insight - on the physiological role of nitric oxide in the visual system
}

\author{
Javier Cudeiro, Casto Rivadulla
}

\begin{abstract}
Research in the fields of cellular communication and signal transduction in the brain has moved very rapidly in recent years. Nitric oxide (NO) is one of the latest discoveries in the arena of messenger molecules. Current evidence indicates that, in visual system, NO is produced in both postsynaptic and presynaptic structures and acts as a neurotransmitter, albeit of a rather unorthodox type. Under certain conditions it can switch roles to become either a neuronal 'friend' or 'foe'. Nitric oxide is a gas that diffuses through all physiological barriers to act on neighbouring cells across an extensive volume on a specific time scale. It, therefore, has the opportunity to control the processing of vision from the lowest level of retinal transduction to the control of neuronal excitability in the visual cortex.
\end{abstract}

Keywords: Nitric oxide; Vision; Retina; LGN; Visual cortex; NMDA; Development

Visual processing starts in the retina. Here, the image of the world is broken down through visual filters (the receptive fields of individual neurones). In mammals this visual message then moves to an intermediate station in the thalamus, the dorsal lateral geniculate nucleus (dLGN). This is a laminar structure that receives the ganglion-cell axons in an organized manner depending on the eye from which the image originated, the cell type and other species-dependent characteristics. Finally, this information is relayed to the primary visual cortex (V1) from which connections are made with many other visual cortical and sub-cortical structures. At every level of this pathway, including the retina, passage of the visual message involves the activation of members of the family of excitatory-amino-acid receptors. However, besides these specific visual signals, there is also modulation of the visual message by a number of non-specific inputs (for example, dopaminergic, cholinergic and noradrenergic), which control the excitability of the neurones and gate the flow of information. Recently, a newly discovered neurotransmitter has emerged rather spectacularly that is involved in the processing of visual information - nitric oxide (NO).

\section{Nitric oxide: ubiquitous neurotransmitter or 'saint-sinner'?}

Since NO was first recognized as a messenger molecule in the brain that mediates the increased cGMP levels that occur on activation of NMDA receptors ${ }^{1}$, major efforts have been made to understand the extent of its actions. Nitric oxide is a gas synthesized from l-arginine by the enzyme nitric-oxide synthase (NOS). At least three forms of the enzyme have been characterized: the constitutive endothelial and neuronal types are both $\mathrm{Ca}^{2+}$ dependent and the third is a $\mathrm{Ca}^{2+}$-independent inducible isoform, which is expressed only in the presence of cytokines. In this review, only data related to neuronal NOS (nNOS) will be considered. Available data from immunocytochemistry, in situ hybridization and NADPHdiaphorase histochemistry have given a reasonably comprehensive picture of the anatomical localization of NO-generating cells and their processes throughout the CNS ( Ref. 2). The brain contains the highest level of NOS of any tissue so far examined and the broad distribution of the enzyme suggests that NO could be involved in many aspects of CNS function ${ }^{1}$.

However, NO might be a 'double-edged sword'. In some studies it has been considered to be potentially neurotoxic ${ }^{3}$. Indeed, in the presence of factors such as oxidative stress, generation of reactive oxygen intermediates and deficient antioxidant systems, $\mathrm{NO}$ can induce neural death ${ }^{4}$. The majority of evidence indicates that the participation of $\mathrm{NO}$ in neurodegenerative phenomena occurs through a nonenzymatic reaction with the superoxide anion $\left(\mathrm{O}_{2}{ }^{-}\right)$to form peroxynitrite $\left(\mathrm{ONOO}^{-}\right)$(see Table 1), which is a highly reactive molecule and a potent oxidizing agent ${ }^{5}$. Other mechanisms of NO toxicity, by DNA damage $^{6}$ or glutathione depletion ${ }^{7}$ have also been postulated. However, these pathological effects remain, 
to some extent, controversial and confusing. Some laboratories using brain-slice or primary-tissue-culture models of glutamate neurotoxicity have reported that NO is also involved in these pathologies ${ }^{8 \text { and } 9}$, while others, employing similar methods, have shown no obvious role ${ }^{10}$ and 11. Furthermore, there is also much evidence to suggest that NO might be neuroprotective ${ }^{12,13 \text { and } 14}$. Differences between the effects of NO have been attributed, at least in part, to different redox-related species of the NO group and their disparate chemical activities. Neurodestruction has been attributed to peroxynitrite alone and not to $\mathrm{NO}^{-}$(the reduced form), and the neuroprotective properties of $\mathrm{NO}$ have been attributed to $\mathrm{NO}^{+}$(the oxidized form), as this species downregulates NMDA-receptor activity by reaction with thiol group(s) in the redox modulatory site of the receptor ${ }^{15,16}$ and 17 (Fig. 1).

Table 1. Products and targets of neuronal nitric oxide synthase ${ }^{\mathrm{a}}$

\begin{tabular}{ll}
\hline Nitric oxide-related species & Principal biological target-reactants \\
\hline & \\
$\mathrm{N}_{2} \mathrm{O}$ & Metals, hydrophobic pockets \\
$\mathrm{NH}_{2} \mathrm{OH}$ & Oxidants \\
$\mathrm{NO}^{-}(\mathrm{MNO} ; \mathrm{SNO})$ & Thiols, metals, oxygen \\
$\mathrm{NO}(\mathrm{MNO} ; \mathrm{SNO})$ & Thiols, metals, superoxide, oxygen \\
$\mathrm{NO}_{\mathrm{x}}-\mathrm{SNO}-\mathrm{MNO}\left(\mathrm{NO}^{+}\right)$ & Thiols \\
$\mathrm{OONO}^{-}$ & Thiols, metals, tyrosine, methionine \\
$\mathrm{NO}_{2}^{-}-\mathrm{NO}_{3}^{-}$ & - \\
& \\
\hline
\end{tabular}

\footnotetext{
a All of the above nitric oxide (NO)-related species have been identified from purified preparations of neuronal nitric oxide synthase $(\mathrm{NOS})^{94}$. The cellular availability of substrates and cofactors appears to influence the oxidation state of the NOS product. Nitrous oxide $\left(\mathrm{N}_{2} \mathrm{O}\right)$ and hydroxylamine $\left(\mathrm{NH}_{2} \mathrm{OH}\right)$ are end-reduction products, while nitrite-nitrate $\left(\mathrm{NO}_{2}{ }^{-}-\mathrm{NO}_{3}{ }^{-}\right)$are end-oxidation products. The remaining compounds have different biological actions and potential toxicities that reflect their chemistry in different redox milieu ${ }^{95,96 \text { and } 97}$. Note that different $\mathrm{SNO}$ and MNO species might function as $\mathrm{NO}^{\prime}, \mathrm{NO}^{+}$, or $\mathrm{NO}^{-}$donors. Adapted, with permission, from Ref. 22.
} 


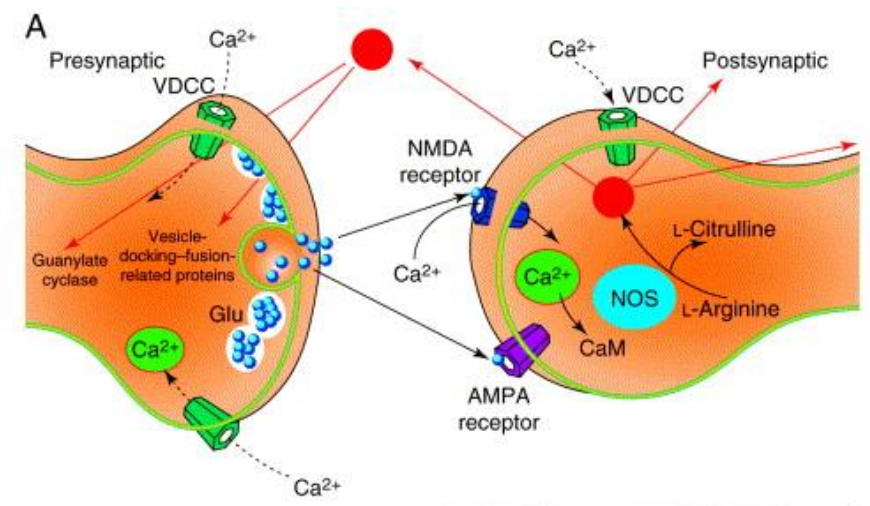

B

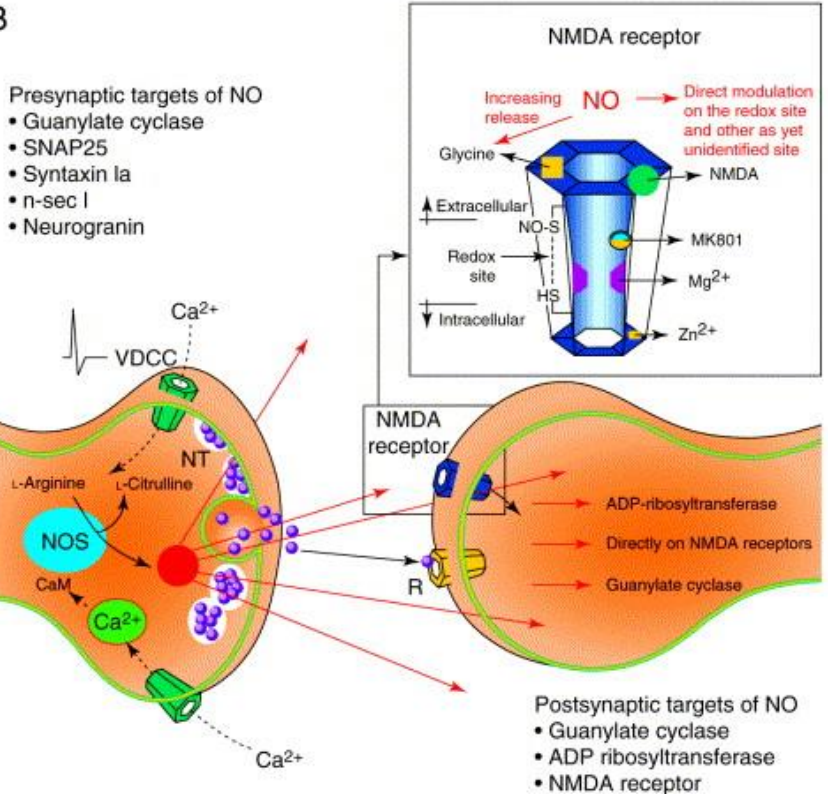

Fig. 1. Presynaptic and postsynaptic locations of nitric-oxide synthase (NOS) and the probable routes of action of nitric oxide (NO).(A) Postsynaptic location of NOS, showing possible presynaptic actions (red arrows). Calcium signal from glutamatemediated activation of NMDA receptors or voltage-dependent $\mathrm{Ca}^{2+}$ channels (VDCCs) binds calmodulin (CaM) and activates NOS, producing NO and citrulline from 1-arginine (reviewed in Ref. 1). The free diffusion of NO suggests that this presynaptic activity need not necessarily be restricted to the presynaptic boutons directly involved with this postsynaptic element. (B) Presynaptic location of NOS, showing possible postsynaptic actions. Note the direct actions on the NMDA receptor, which is expanded in the inset box and shows the different modulatory sites. Neurotransmitter (NT) release is triggered by the arrival of an action potential in the presynaptic terminal by the opening of VDCCs. The resulting elevation in the internal $\mathrm{Ca}^{2+}$ concentration, is the signal that causes NO production. This has been shown to occur in the dorsal lateral geniculate nucleus of the cat ${ }^{18,19 \text { and } 20}$, where NOS is colocalized with ACh within the axons arising from the brainstem ${ }^{21}$. Again, diffusion of NO can induce actions on sites that are remote from the synapse illustrated here. Therefore, the possibility of combined presynaptic and postsynaptic activities from either NOS location cannot be excluded. Abbreviations: Glu, glutamate; SNAP25, 25 kDa synaptosomal-associated protein.

To complete this brief overview, and yet add another level of complexity, it is important to make clear that, although the best recognized effectors for NO are adenylate cyclase and cGMP, they are not the only ones and many NO-mediated effects are cGMP independent. These pathways have typically been grouped under the broad heading of redox-related NO signals and can be well-regulated post-translational modifications that are part of cellular control mechanisms ${ }^{22}$. In neurones several enzymes, $G$ proteins, transcription factors, transporters and ion channels are targets for NO (Table 2). 
Table 2. Neuronal targets of nitric oxide-related species ${ }^{\mathrm{a}}$

\begin{tabular}{llc}
\hline Targets & Effect & Refs \\
\hline & & LTP, modulation of visual processing at the level of primary visual cortex \\
Guanylate cyclase & Neuroprotection, facilitation of NMDA-mediated responses in dLGN & 98 \\
NMDA receptor & Synaptic plasticity and transmission & 99 \\
SNAP25 & Synaptic vesicle docking-fusion & 99 \\
Syntaxin 1a & Synaptic vesicle docking-fusion & 100 \\
$\mathrm{n}-\mathrm{sec} 1$ & LTP, neurotransmitter release & 101 \\
Neurogranin & Vesicular glutamate uptake & 102 \\
$\mathrm{H}^{+}-$ATPase & Olfactory transduction, visual transduction, modulation of retinal ganglion- \\
Cyclic & cell activity & 103 \\
channel & Retinal photoreceptor function & 99 \\
$\mathrm{Ca}^{2+}$ channel (rods) & Ion homeostasis & 104 \\
$\mathrm{Na}^{+} / \mathrm{K}^{+}$-ATPase & & \\
?VAMP & LTP, modulation of visual transduction & \\
ADP ribosyltransferase & & \\
\end{tabular}

Thus, in brief, NO seems to be an almost-ubiquitous messenger substance in the CNS that can, under certain conditions (such as its excessive production or the absence of regulatory control mechanisms), be toxic to cells, while possibly also being capable of acting as a neuroprotectant. However, under normal, physiological conditions NO seems to act as a neurotransmitter, albeit of a novel and unusual type. Within the more restricted field of sensory neurobiology there currently exists a lesser but no less significant interest in NO. Although NO has been demonstrated at all levels of the sensory CNS and across many modalities, there is a large amount of evidence for its presence and action in the visual system (see Fig. 2). Data exist that show NO has a role in the visual system from retina to cerebral cortex and it seems appropriate that a review of these studies is made. 

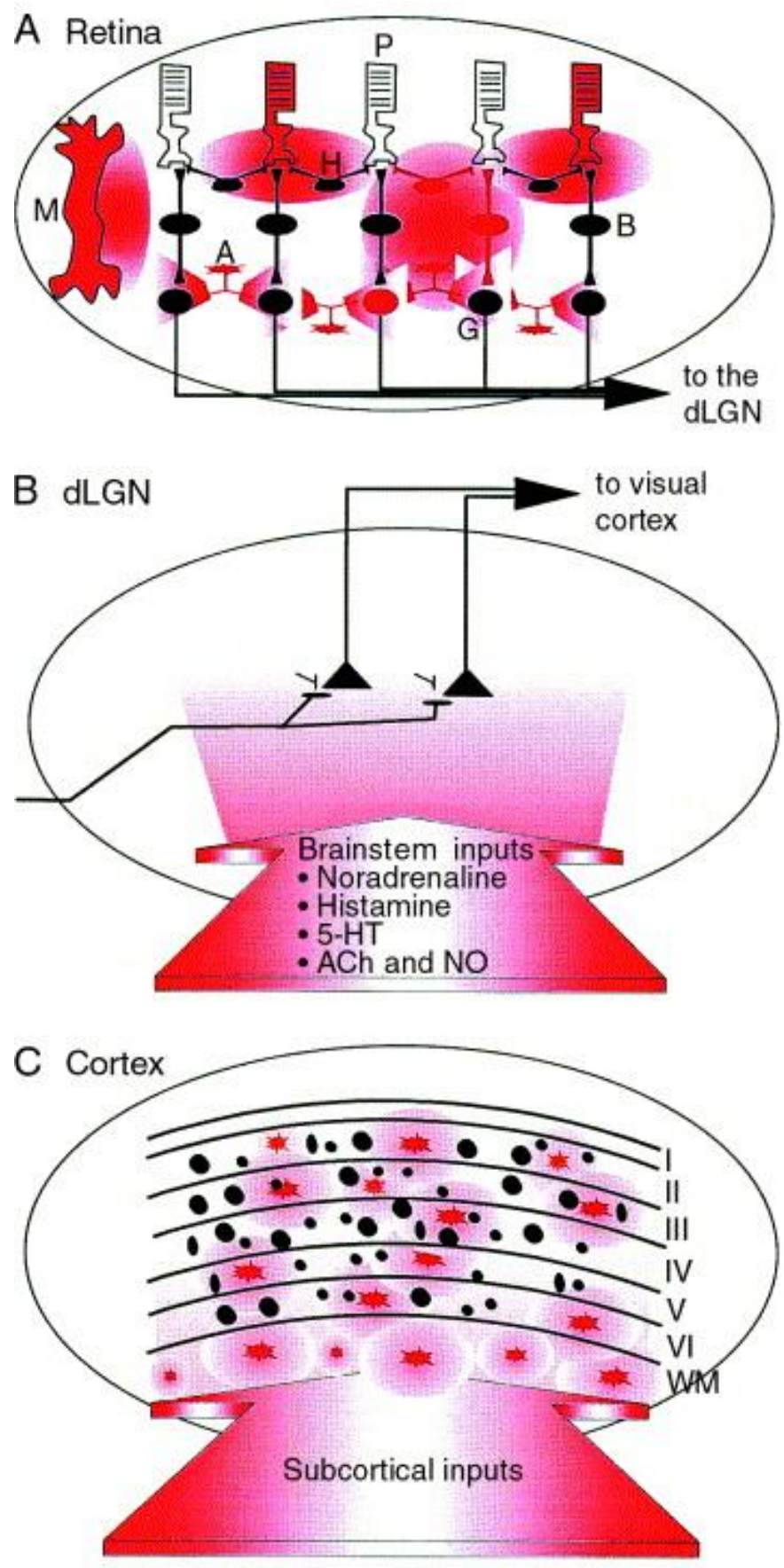

Fig. 2. Distribution of nitric-oxide synthase (NOS) containing cells and NOS positive fibres in the visual system. Summary of the three primary levels of the mammalian visual system. $(A)$ Nitric oxide (NO) is produced in photoreceptors (P), horizontal cells $(\mathrm{H})$, amacrine cells (A), Müller cells (M) and ganglion cells (G) (red) $23,24,25,26,27,28,29,30,31,32,33,34,35$ and 36 . In the retina it regulates phototransduction ${ }^{37}$ and 38 ; modulates photoreceptor output ${ }^{37,39,40,41 \text { and } 42}$, bipolar cells ${ }^{38}$ and horizontal cells ${ }^{43,44,45,46,47,48 \text { and } 49}$; controls ganglion-cell excitability ${ }^{50}$ and modulates the electroretinogram ${ }^{38 \text { and } 51}$. The widespread distribution of NOS-positive cells in these areas gives rise to possible modulation of retinal processes at all three levels by NO. The time course of effects at each level is likely to be similar because the half-life of $\mathrm{NO}$ in vitro has been estimated to be around $6 \mathrm{~s}$ ( Ref. 52) (although in vivo it could be much longer ${ }^{53}$ ). These effects on retinal processing include: (1) regulation of phototransduction (altering levels of cGMP and by ADP ribosylation); (2) modulation of output at photoreceptor synapses (by altering $\mathrm{Ca}^{2+}$ currents); (3) activation of ON-bipolar cells (by acting on its NO-sensitive GC); (4) decreasing the lateral spread of light responses (by decreasing electrical coupling and responsiveness to glutamate in horizontal cells); and (5) controlling ganglion-cell excitability and thereby the retinal output (by acting on cGMP-gated cation channels). (B) In the cat, monkey and human dorsal lateral geniculate nucleus (dLGN) there are no

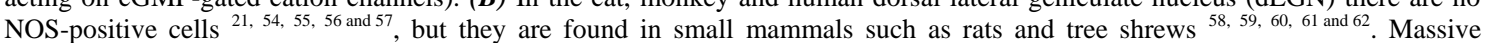
projection of NOS-positive terminals from the brainstem are shown in red ${ }^{21}$. In the dLGN, nitric oxide modulates NMDA-receptor activation, the gating of visual transmission ${ }^{18,19 \text { and } 20}$, the control of oscillatory activity ${ }^{63}$ and has an important role in development in this region ${ }^{64,65,66,67,68,69,70 \text { and } 71}$. (C) Scattered NOS-producing neurones are found in all layers of the cortex (red), many in the white matter (WM) $29,55,57,58,62,72,73$ and 74 . Here NO modulates visual responses via cGMP ( Ref. 75) and is involved in the regulation of presynaptic neurotransmitter release ${ }^{76}$. 


\section{The retina}

In a general scheme of vertebrate retinal physiology, visual excitation in photoreceptors is mediated by the light-triggered hydrolysis of intracellular cGMP and is transmitted via bipolar cells to the output, ganglion-cell layer of the retina. The visual signal is laterally modulated by two major classes of neurones: horizontal cells located in the outer plexiform layer and amacrine cells located in the inner retina. Such modulation is carried out via chemical synapses using a number of different neurotransmitters, and also by electrical coupling ${ }^{77}$. There is now much evidence that demonstrates that NO has a role in the physiological regulation of diverse processes within the retina, from the transduction to the gating of the output signal. These include:

\section{Localization of nitric-oxide synthesis}

Nitric-oxide synthase has been reported to have NADPH-diaphorase (NADPH-d) activity ${ }^{78 \text { and } 79}$ and both histochemical detection of NADPH-d activity and immunoreactivity to antibodies raised against NOS are used extensively as methods for identifying nNOS. These methods have revealed that horizontal, amacrine and ganglion cells of different mammals s, 23, 24, 25, 26, 27 and 28 and non-mammals ${ }^{29}$ and 30 contain nNOS. Moreover, human retinal tissues have been found to express mRNA for constitutive and inducible NOS (Ref. 31). The presence of nNOS activity in photoreceptors has been a matter of controversy. Several studies using immunocytochemical and NADPH-d histochemical staining failed to localize nNOS activity $^{78,80 \text { and } 81}$. Nevertheless, other studies, including the most recent, claim that nNOS activity to be present in the inner and outer segments of photoreceptor rods ${ }^{25}, 26,32,33,34$ and 35 . Furthermore, using NADPH-d histochemistry to study the cone-dominated retina of the tree shrew it has been possible to reveal several patterns of activity in the cellular subcompartments of the spectral classes of cones, which suggests that NO may be differentially involved in the functioning of different classes of photoreceptors $^{36}$. Interestingly, there is also evidence that NOS is found in Müller cells of both fish and amphibian species, suggesting yet another route by which NO can modulate retinal function ${ }^{29}$.

\section{$N O$ affects the metabolism of cGMP in a variety of cells}

(1) Available data show that NO is functionally coupled to a soluble guanylate cyclase and might be able to increase cGMP levels in rod photoreceptors thereby increasing the cGMP-gated conductances ${ }^{37}$, which affect both response amplitude and response kinetics ${ }^{82}$. Nitric oxide has also been shown to modulate $\mathrm{Ca}^{2+}$ channels and transmission of the photoresponse to second-order cells ${ }^{37}$, and to increase adenosine diphosphate (ADP) ribosylation of a variety of proteins such as transducin, G proteins and other, as yet unidentified, proteins in the outer segment of photoreceptor rods ${ }^{39,40 \text { and } 41}$. These alterations of cellular proteins could be a mechanism by which NO modifies the operational mode of enzymes in the visual transduction cascade ${ }^{38}$. Nitric oxide can also modulate $\mathrm{Ca}^{2+}$ and cyclic-nucleotide-gated channels in both rod and cone photoreceptors, which control exocytosis at cone synapses, thereby altering synaptic efficacy $^{42}$ and 83 .

(2) Work carried out in fish has shown that NO donors, NOS inhibitors and NO-related substances modify electrical coupling in horizontal cells in such a way that the presence of cGMP, l-arginine or the NO donor, sodium nitroprusside, decreases electrical and dye-tracer coupling between the cells ${ }^{43}$ and 44 . This modulation of the gap-junctional conductance seems to be produced by activating the cGMPdependent protein kinase $\mathrm{G}$ (PKG) pathway $^{45}$. Nitric oxide might also modify horizontal-cell activity by actions on chemical synapses. For example, NO reduces the responsiveness of glutamate receptors on retinal horizontal cells taken from the hybrid bass retina ${ }^{46}$. Interestingly, while dopamine is known to modify electrical coupling in horizontal cells ${ }^{43}$ and 47 and NO has been shown to modulate dopamine release in the retina ${ }^{48}$, these actions seem separate, because the action on dopamine release seem to affect only $\mathrm{K}^{+}$-mediated release and not basal release ${ }^{49}$. In summary, NO acts to downregulate horizontal-cell activity, which can alter apparent receptive-field size and thus influence the lateral spread of lightresponses in the retina, while at the same time protecting horizontal cells from glutamate excitotoxicity.

(3) Both bipolar and ganglion cells are susceptible to the influence of NO. Guanylate cyclase (GC) of ON-bipolar cells is of the NO-sensitive type and increased levels of cGMP have been reported after the application of NO donors ${ }^{38}$. More recently, a cGMP-gated non-selective cation channel, whose conductance is increased by NO donors, has been found in ganglion cells ${ }^{50}$. Thus, because nNOS activity is present within the ganglion-cell layer, it is plausible that a NO-cGMP system exists there that modulates retinal output. 
All the studies mentioned so far have been carried out using in vitro preparations (mainly dissociated cells). Without doubt these have been useful and have made it possible to investigate problems that are otherwise unexaminable by current in vivo techniques. However, the disruption of the functional anatomy of the retina can clearly alter response properties of this complex system, which makes the use of different and complementary experimental approaches necessary. Recent studies that recorded the electroretinogram (ERG) in the intact cat eye ${ }^{38}$ or both ERG and compound action potentials from the optic nerve in the intact rabbit retina ${ }^{51}$ during application of NO-related compounds suggest that NO contributes physiologically to retinal processing.

\section{The thalamus}

In mammals, the dLGN plays a pivotal role in the transmission of visual information to the cerebral cortex. Unlike the retina, this is a site where both processing and gating of information takes place thalamic transmission can be modulated by a number of inputs that arise from the brainstem ${ }^{84}$ and are dependent upon the behavioural state of the organism. Moreover, processing and gating in the dLGN are also functions that are intimately associated with, and regulated by, neural functioning in the visual cortex, by virtue of the large descending corticofugal input.

Neuronal NOS activity has been found in the thalamus of variety of species. For example, NADPH-dpositive cells have been seen in the ventral division of the LGN in rats and tree shrews ${ }^{58 \text { and } 59}$, and NADPH-d reactivity and GABA (Ref. 60) are co-localized in a subpopulation of local inhibitory interneurones in the dLGN of the rat ${ }^{61}$. Furthermore, NOS activity has also been detected in the visual thalamus by immunocytochemistry ${ }^{62}$. Interestingly, in higher mammals, such as the cat, the monkey and human beings, the dLGN are completely devoid of nNOS-containing neurones, although a dense network of axons and terminals are labelled (Fig. 2B; 54, 55, 56 and 57). Recent evidence has shown that the cat dLGN contains a unique distribution of nNOS, found exclusively within the cholinergic fibres that originate in the parabrachium ${ }^{21}$. This represents a novel co-localization of neurotransmitters and shows an exclusively presynaptic location for nNOS. It has been demonstrated in vivo that NO can potently enhance those visual responses that are due specifically and selectively to NMDA-receptor-mediated excitation in this region ${ }^{18,19}$ and 20 (Fig. 3B). Such an action is likely to be postsynaptic in origin and does not involve cGMP ( 19 and 20). This in vivo discovery is puzzling because it is contrary to what has been reported by several groups using in vitro models, where NO inhibits NMDA-receptor channels by an action on the redox modulatory site ${ }^{15}$. One possible explanation is that because, as already outlined, NO

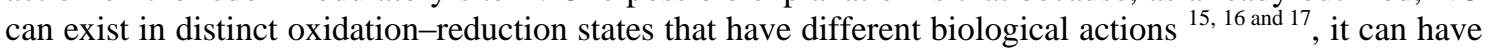
opposite effects depending on the local redox milieu. However, there are also reports that NO affects NMDA-mediated activity independently of cGMP and the NMDA-associated redox site ${ }^{85}$. It has even been suggested that NO might modulate NMDA currents by stimulating the release of glycine, the cofactor for NMDA activation ${ }^{86}$ (see Fig. 1). Other experiments in cat dLGN in vitro showed that application of NO to thalamocortical neurones had a direct postsynaptic depolarizing effect that was associated with a decrease in input resistance. These small depolarizations appeared to act via the cGMP second-messenger system and relate to the control of oscillatory firing patterns ${ }^{63}$ ( Fig. 3C). This cGMPmediated action of NO might be involved in the control of different patterns of electrogenic activity during various states of the sleep-wake cycle. However, the demonstrable effects of the block of nNOS in vivo do not operate via the cGMP cascade, as the soluble cGMP analogue, 8-bromo-cGMP, has been shown not to affect NMDA-mediated excitation or mimic the effect of NO donors ${ }^{19}$. 


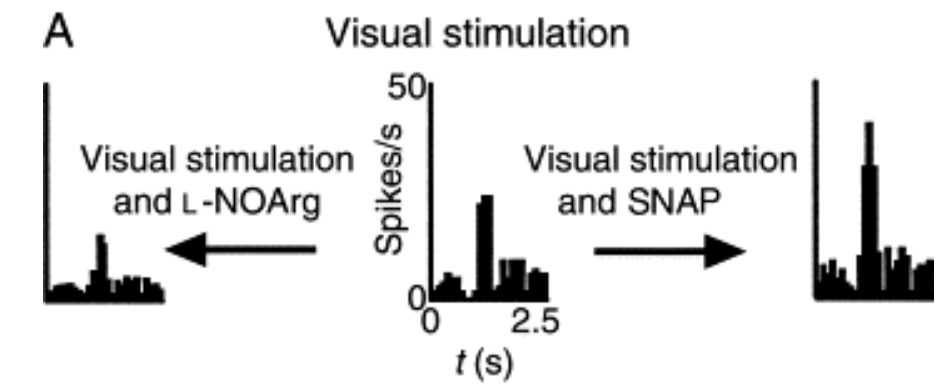

Visual stimulation

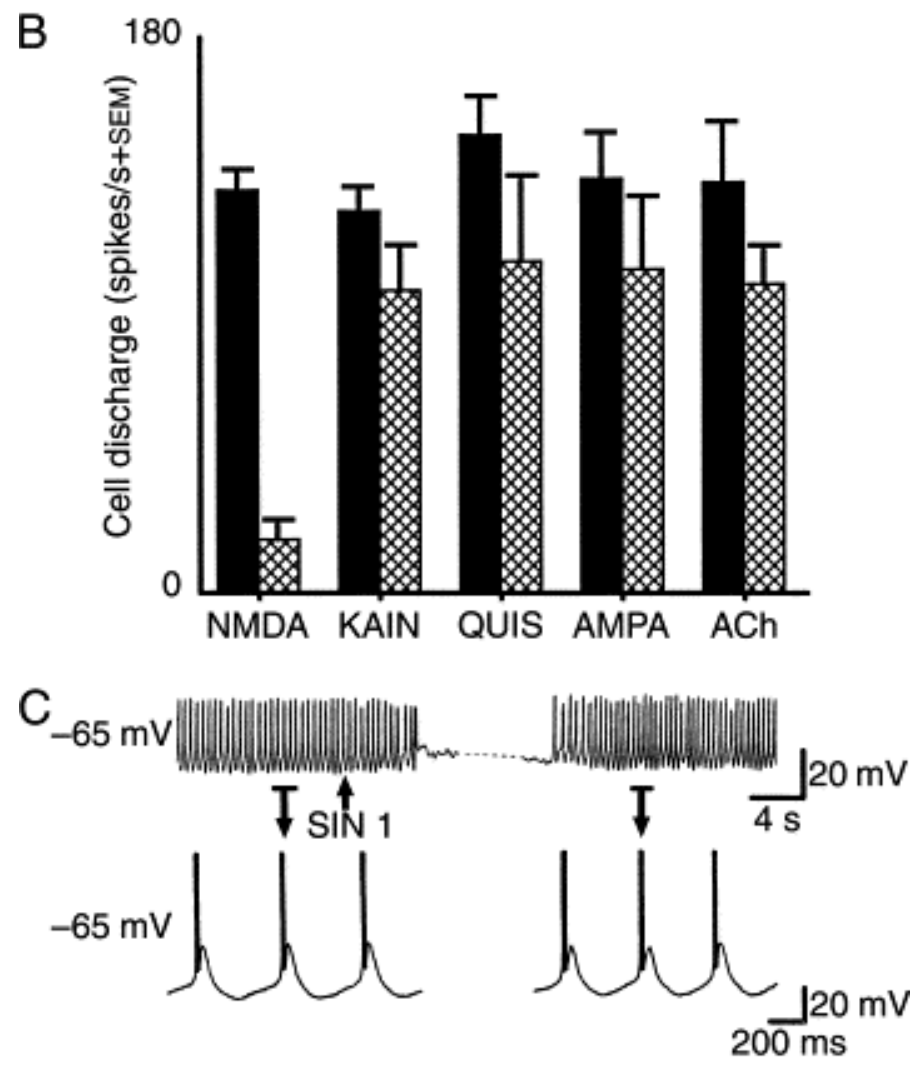

Fig. 3. Summary of the actions of the nitric-oxide system in the feline dorsal lateral geniculate nucleus (dLGN).(A) Control visual responses to small spot of light centred over the receptive field centre (centre). Application of the nitric-oxide (NO) donor, snitroso- $N$-acetyl-(d,1)-penicillamine (SNAP), increases responsiveness (right). Application of 1-NOArg, a nitric-oxide synthase (NOS) inhibitor, suppresses visual responses (left). Adapted, with permission, from Ref. 20. (B) Histogram showing that application of the NOS antagonist, 1-NOArg, depresses responses to applied NMDA in a highly selective fashion, compared to similar tests with the other drugs KAIN (kainic acid), QUIS (quisqualic acid), AMPA and ACh. Reproduced, with permission, from Ref. 19.(C) Intracellular recordings of a feline geniculate cell in vitro. Example of a neurone that spontaneously generates rhythmic Ca ${ }^{2+}$ mediated burst activity. Generation of NO through SIN 1 reversibly inhibits this activity. Indicated segments are expanded for details. Adapted, with permission, from Ref. 63.

In summary, in the visual thalamus it can be hypothesized that NO can act wherever brainstem parabrachial terminals arborize, with production regulated by activity levels in these fibres in a $\mathrm{Ca}^{2+}$ dependent manner. While the basal release of NO can contribute to control of oscillatory activity, which is dependent on the behavioural status of an organism, it can also facilitate visual transmission from the retina through the dLGN to the cortex, particularly when such transmission invokes the activation of voltage-dependent NMDA receptors. Furthermore, NO might affect simultaneously the functional status of a relatively large neuronal population by local diffusion. Indeed, a theoretical model has predicted that the sphere of influence of a single point source of NO has a diameter of about $200 \mu \mathrm{m}$, corresponding to a volume in the brain that encloses up to two million synapses ${ }^{1}$. 
A role for NO in development has been described in different species. In rats, the superior colliculus is a major target for retinal axons and the refinement of retinocollicular connections takes place during the first few postnatal weeks. Given that nNOS is expressed in the retinorecipient layers of the rat superior colliculus during this period, it has been suggested that NO has a role in synaptic refinement ${ }^{64 \text { and } 65}$. Similarly, in the chick, the superficial layers of the optic tectum are the main sites for termination of retinal axons. Prior to the innervation by retinal axons, NADPH-d-stained cells are found only in deep layers. When axons innervate this area, NADPH-d-positive cells appear in the superficial layers, progressively increasing in number until the peak period for remodelling of retinal connections, which coincides with the loss of several transient projections, occurs. This loss is reduced if NO synthesis is inhibited $^{66}$. Although the exact mechanism by which NO mediates this effect is not clearly understood, it has been suggested that coordinated activity in the major inputs, NMDA-receptor activation and NO production could each have a key role ${ }^{66}$. Interestingly, in the tadpole explanted retina, application of NO donors results in the collapse of active growth cones of ganglion-cell axons; such a mechanism could explain the termination of axonal growth at the tectal level during development ${ }^{67}$.

Similar results have been found in the dLGN of the ferret and the cat where NOS is transiently expressed during the period in which projections from the retina are refined ${ }^{68 \text { and }} 69$. In the ferret dLGN, retinal information is segregated into $\mathrm{ON}-\mathrm{OFF}$ sublaminae, a process that requires NMDA-receptor activation, and application of a NOS inhibitor resulted in an overall pattern of sublamination that was clearly reduced when compared with normal animals ${ }^{70}$. In the developing kitten (by contrast with the adult cat), NADPH-d staining of dLGN cells suggested that NO might act in a retrograde fashion and perhaps have a role in the maintenance of associative processes that underlie activity-dependent refinement of retinogeniculate connections ${ }^{69}$. Further indirect results on the putative role of NO on development and plasticity have also been obtained in cats. After monocular lid suturing as kittens, adult cats showed an abnormal presence of NADPH-d-positive cells within the dLGN, which was not seen in normally reared controls, clearly indicating that NOS activity can be induced (or perhaps retained) by visual deprivation ${ }^{71}$.

\section{Visual cortex}

In the cerebral cortex, NO production could arise from several possible sources (see Fig. 2C): extrinsically from cholinergic fibres that originate in the forebrain ${ }^{87}$; from cortical blood vessels capable of NO production from endothelial cells of blood-vessel walls ${ }^{88}$ and intrinsically from cells within the cortex that contain nNOS (a subset of the non-spiny cortical cells ${ }^{58}$ and 78 ). Neurones containing nNOS were observed scattered throughout all cortical regions (Fig. 4) from layers II to VI and in the subcortical white matter in several species including the rat $^{58 \text { and } 62}$, cat $^{72}$, monkey ${ }^{55}$ and 73 and human beings ${ }^{57 \text { and } 74}$. Such a diversity of production sites suggests a complex role or roles for NO in cortical visual processing. Examples to support this include: (1) in primate, the distribution of NADPH-d staining is closely aligned with that of cytochrome oxidase and shows a similar laminar and spatial distribution ${ }^{73}$. This could suggest a role for NOS that is associated with parvocellular, wavelength selective neurones. (2) Recent evidence has shown that NO might be involved in the NMDA-mediated release of noradrenaline and glutamate from rat cortical synaptosomes, thereby suggesting that NO has both direct actions in the visual cortex and actions on modulatory processes ${ }^{76}$. Investigations centred specifically on the visual cortex of the anaesthetized cat have shown that application of compounds that manipulate the NO system alter responsiveness of a substantial proportion of neurones to visual stimuli, either reducing or augmenting visual responses. This regulation of cortical visual processing seems to be mediated via the cGMP second-messenger system ${ }^{75}$ (Fig. 5) and suggests the existence of both upregulation and downregulation of cellular firing in separate subpopulations of cortical cells, which could be related to the level of cholinergic neurone activity in these cells and with changes in the state of arousal of the animal. 
A

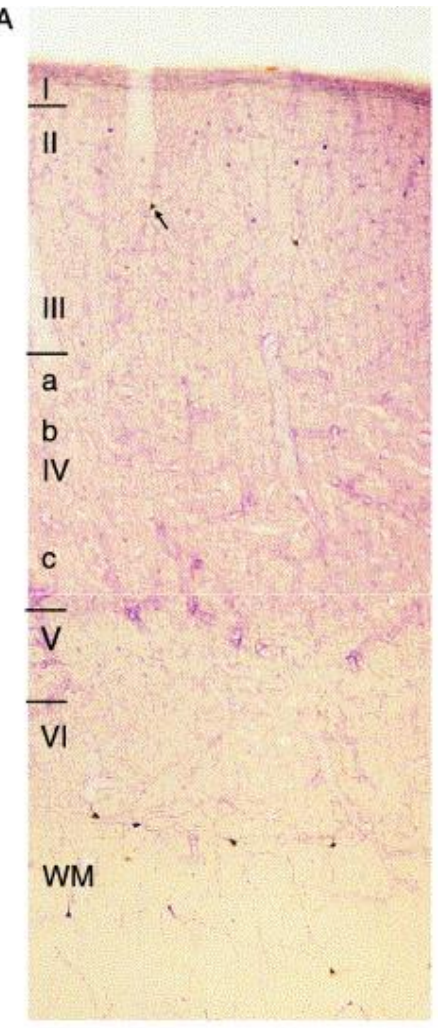

B
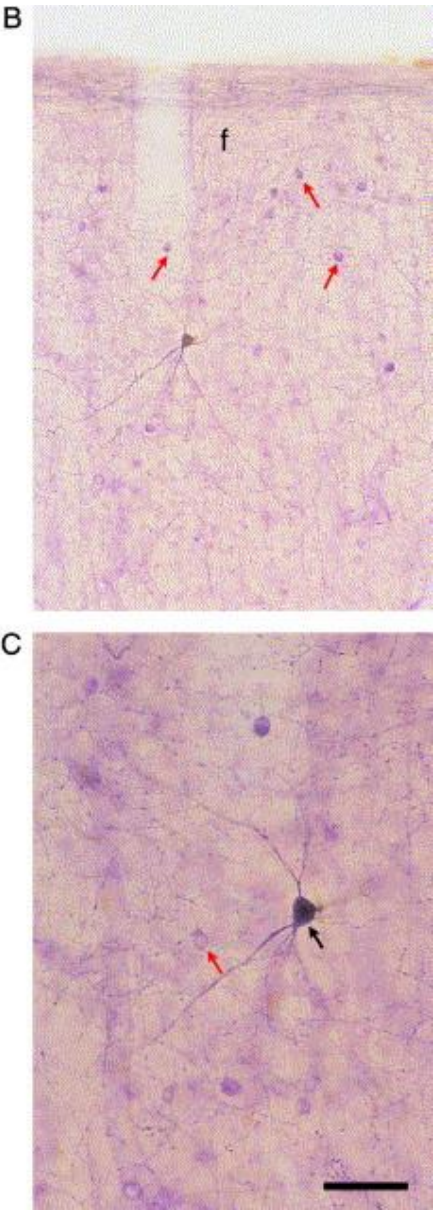

Fig. 4. NADPH-diaphorase staining in macaque primary visual cortex. Photomicrographs of NADPH diaphorase-positive neurones and fibres in the visual cortex (area V1) of a macaque monkey stained according to the protocol of Hope and Vincent ${ }^{89}$. Moderately and darkly stained neurones are localized mainly in layers II, the upper half of layer III, the lower third of layer VI, and in the white matter. $(\boldsymbol{A})$ Low-power photomicrograph from layer I to the white matter (WM). The black arrow indicates a strongly stained nonpyramidal cell that is also shown at higher magnification in $(B)$ and $(C)$. $(\boldsymbol{B})$ Photomicrograph from layers I to III showing numerous lightly or moderately stained neurones (red arrows) and the plexus of horizontally oriented fibres (f) located in the upper half of layer I. $(\boldsymbol{C})$ High-power photomicrograph of the darkly stained cell (black arrow) also indicated in $(A)$ and $(B)$. Note the dense network of fibres running in all directions. The red arrow indicates a lightly labeled neurone. Scale bar, $172 \mu \mathrm{m}$ in $(A), 75 \mu \mathrm{m}$ in $(B)$ and $35 \mu \mathrm{m}$ in $(C)$. The photomicrographs were provided by Dr Javier DeFelipe, Cajal Institute, Spain. Cortical neurones synthesizing nitric oxide are currently visualized with NADPH-diaphorase histochemistry or immunocytochemistry for neuronal nitric-oxide synthase (nNOS). These neurones mainly represent a subpopulation of GABAergic non-pyramidal cells (interneurones) that contain the peptides somatostatin and neuropeptide $\mathrm{Y}$, and frequently contain the $\mathrm{Ca}^{2+}$-binding protein calbindin, but not parvalbumin and calretinin. These GABAergic cells also show little or no co-localization with the peptides cholecystokinin, vasoactive intestinal polypeptide, the tachykinins or corticotropin releasing factor ${ }^{90}$. 


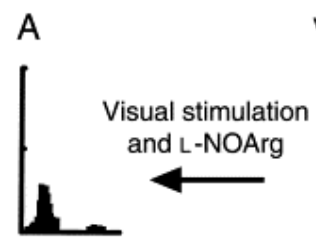

Visual stimulation
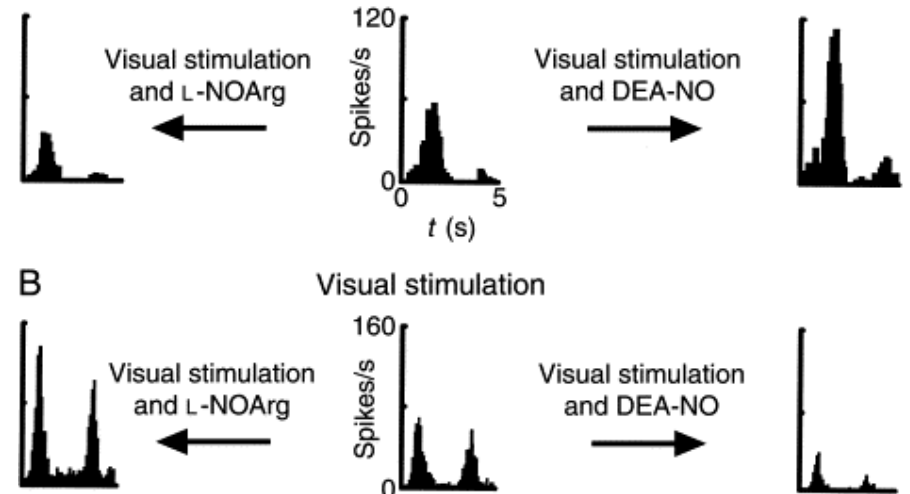

Visual stimulation
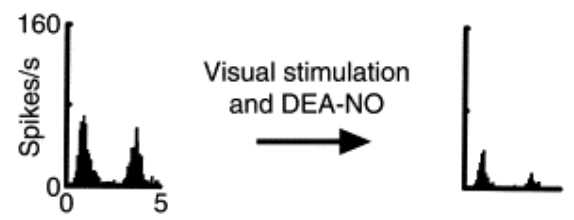

$t(\mathrm{~s})$

Fig. 5. Peri-stimulus time histograms illustrating the range of activities of nitric oxide (NO) and related compounds in cat visual cortex.(A) Control visual response of a directionally selective complex cell (centre). Application of DEA-NO, a NO donor, increases the response to the stimulus (right). Application of 1-NOArg, a NOS inhibitor, decreases the same response (left). (B) Control visual responses of a non-directionally selective complex cell (centre). DEA-NO causes almost complete response suppression (right). 1-NOArg application greatly increases responses in both directions equally (left). Drugs were applied by iontophoresis and responses averaged over a number of stimulus trials. Cells were driven monocularly through the dominant eye and the stimulus orientation selected from a quantitatively derived orientation tuning curve. Adapted, with permission, from Ref. 75 .

Interestingly, in contrast to studies mentioned above that show a role for NO in the development of subcortical visual structures, there is no evidence to date to suggest a similar developmental role for NO in the visual cortex ${ }^{91}$ and 92 , even though NOS distribution in visual cortex can be altered by manipulation of visual inputs 55 .

\section{Concluding remarks}

One of the most intriguing features of NO, considering the simplicity of the molecule, is that it is involved in so many different regulatory functions and has many other effects. At low concentrations, it can work as a neuromodulator or a retrograde messenger in the CNS; at relatively high concentrations it can be toxic. It is tempting to speculate that NO could have multiple roles in separate regions and circuits, each role related to local physiological functions and not necessarily part of the more general role that NO has in neurotoxicity or neuroprotection. These represent alterations of normal homeostatic function of the $\mathrm{CNS}$ and its regulatory mechanisms. It is important to note the significance of in vivo studies and to understand the need for studies of the physiology of whole systems.

Nitric oxide, the gas, the common air pollutant, the suspected carcinogen and the destroyer of ozone could be the archetypal example used to illustrate the concept of 'parasynaptic' information transmission in the brain, a domain of versatility and plasticity, as formulated by Schmitt ${ }^{93}$ '...new ways of conceptualization of information-transactional chemical processes as applied to basic concepts of neurobiology', in this case to the concept of vision.

\section{Acknowledgements}

The author's research was supported by XUGA(13401B96), FIS(97/0402) and Vicerrectorado de Investigación (Universidade da Coruña), Spain. We are indebted to Dr Kenneth L. Grieve for helpful comments and corrections. 


\section{References}

1. J. Garthwaite, C.L. Boulton. Annu. Rev. Physiol., 57 (1995), pp. 683-706

2. S.R. Vincent. Prog. Neurobiol., 42 (1994), pp. 129-160

3. J.B. Schulz, T.M. Russell, F. Beal. Curr. Opin. Neurol., 8 (1995), pp. 480-486

4. H.H.H. Schmidt, U. Walter. Cell, 78 (1994), pp. 919-925

5. Beckman, J.S. (1996) in Nitric Oxide. Principles and Actions (Lancaster, J., Jr, ed.), pp. 1-82, Academic Press

6. J. Zhang, et al. Science, 263 (1994), pp. 687-689

7. R.M. Clancy, et al. Proc. Natl. Acad. Sci. U. S. A., 91 (1994), pp. 3680-3684

8. Y. Izumi, et al. Neurosci. Lett., 135 (1992), pp. 227-230

9. V.L. Dawson, et al. J. Neurosci., 13 (1993), pp. 2651-2661

10. C. Demerlé-Pallardy, et al. Biochem. Biophys. Res. Commun., 181 (1991), pp. 456-464

11. G. Garthwaite, J. Garthwaite. Neuropharmacology, 33 (1994), pp. 1431-1438

12. I. Hanbauer, et al. NeuroReport, 3 (1992), pp. 409-412

13. L. Kiedrowski, E. Costa, J.T. Wrobleski. Mol. Pharmacol., 41 (1992), pp. 779-784

14. D.A. Wink, et al. Proc. Natl. Acad. Sci. U. S. A., 90 (1993), pp. 9813-9817

15. S.Z. Lei, et al. Neuron, 8 (1992), pp. 1087-1099

16. S.A. Lipton, et al. Nature, 364 (1993), pp. 626-632

17. Z.-H. Pan, M.M. Segal, S.A. Lipton. Proc. Natl. Acad. Sci. U. S. A., 93 (1996), pp. 15423-15428

18. J. Cudeiro, et al. J. Neurophysiol., 71 (1994), pp. 146-149

19. J. Cudeiro, et al. Neuropharmacol., 33 (1994), pp. 1413-1418

20. J. Cudeiro, et al. Eur. J. Neurosci., 8 (1996), pp. 144-152

21. M.E. Bickford, et al. J. Comp. Neurol., 334 (1993), pp. 410-430

22. J.S. Stamler, et al. Neuron, 18 (1997), pp. 691-696

23. J.H. Sandell. J. Comp. Neurol., 238 (1985), pp. 466-472

24. J. Mitrofanis. Neurosci. Lett., 102 (1989), pp. 165-172

25. N.N. Osborne, N.L. Barnett, A.J. Herrera. Brain Res., 610 (1993), pp. 194-198

26. R. Yamamoto, et al. Neuroscience, 54 (1993), pp. 189-200

27. K.R. Huxlin, M.R. Bennett. Eur. J. Neurosci., 7 (1995), pp. 2226-2239

28. M.T.R. Perez, et al. Exp. Brain Res., 104 (1995), pp. 207-217

29. B.A. Liepe, et al. J. Neurosci., 14 (1994), pp. 7641-7654

30. T. Östholm, et al. Neurosci. Lett., 168 (1994), pp. 233-237

31. C-S. Park, et al. Biochem. Biophys. Res. Commun., 205 (1994), pp. 85-91

32. S.M. Sagar. J. Comp. Neurol., 300 (1990), pp. 309-319

33. C.M. Venturini, et al. Biochem. Biophys. Res. Commun., 180 (1991), pp. 920-925

34. K-W. Koch, et al. EMBO J., 13 (1994), pp. 3312-3320

35. A. Yoshida, et al. Visual Neurosci., 12 (1995), pp. 493-500

36. H.M. Petry, H.A. Murphy. Proc. Natl. Acad. Sci. U. S. A., 92 (1995), pp. 5121-5123

37. D.E. Kurenny, et al. Neuron, 13 (1994), pp. 315-324

38. I.M. Goldstein, P. Ostwald, S. Roth. Vis. Res., 36 (1996), pp. 2979-2994

39. B. Brune, E.G. Lapetina. Arch. Biochem. Biophys., 279 (1990), pp. 286-290

40. S. Ehret-Hilberer, et al. Fed. Eur. Biochem. Soc., 309 (1992), pp. 394-398

41. N. Pozdnyakov, et al. Biochem. Biophys. Res. Commun., 192 (1993), pp. 610-615

42. F. Rieke, E.A. Schwartz. Neuron, 13 (1994), pp. 863-873

43. S.H. DeVries, E.A. Schwartz. J. Physiol., 414 (1988), pp. 351-375

44. E. Miyachi, M. Mukarami, T. Nakaki. NeuroReport, 1 (1990), pp. 107-110

45. C. Lu, D.G. McMahon. J. Physiol., 499 (1997), pp. 689-699

46. D.G. McMahon, L.V. Ponomareva. J. Neurophysiol., 76 (1996), pp. 2307-2315

47. D.G. McMahon, A.G. Knapp, J.E. Dowling. Proc. Natl. Acad. Sci. U. S. A., 86 (1989), pp. 76397643

48. O. Bugnon, N.C. Schaad, M. Schorderet. NeuroReport, 5 (1994), pp. 401-404

49. M. Pottek, K. Schultz, R. Weiler. Vis. Res., 37 (1997), pp. 1091-1102

50. I. Ahmad, et al. Neuron, 12 (1994), pp. 155-165

51. K.I. Maynard, P. Yanez, C.S. Ogilvy. NeuroReport, 6 (1995), pp. 850-852

52. R.E. Furchott, P.M. Vanhoutte. FASEB J, 3 (1989), pp. 2007-2018

53. A. Meulemans. Neurosci. Lett., 171 (1994), pp. 89-93

54. K. Mizukawa, et al. J. Comp. Neurol., 279 (1989), pp. 281-311

55. C. Aoki, et al. Brain Res., 620 (1993), pp. 97-113

56. K. Satoh, et al. Neuroscience, 66 (1995), pp. 685-696

57. Y.I. Egberongbe, et al. Neuroscience, 59 (1994), pp. 561-578 
58. S.R. Vincent, H. Kimura. Neuroscience, 46 (1992), pp. 755-784

59. S. Agarwala, et al. J. Comp. Neurol., 218 (1992), pp. 267-276

60. J. Mitrofanis. Visual Neurosci., 9 (1992), pp. 211-216

61. P.L.A. Gabbott, S.J. Bacon. J.Comp. Neurol., 350 (1994), pp. 281-301

62. J. Rodrigo, et al. Phil. Trans. R. Soc. London Ser. B, 345 (1994), pp. 175-221

63. H-C. Pape, R. Mager. Neuron, 9 (1992), pp. 441-448

64. T. Gonzalez-Hernandez, M. Conde-Sendin, G. Meyer. Anat. Embryol., 186 (1992), pp. 245-250

65. G. Prusky, M. Hofer, M. Constantine-Paton. Soc. Neurosci. Abstr., 18 (1992), p. 1311

66. Wu, H.H., Waid, D.K. and McLoon, S.C. (1996) in Prog. Brain Res. (Vol. 108) (Mize, R.R. and Erzurumlu, R.S., eds), pp. 273-286, Elsevier

67. R.C. Renteria, M. Constantine-Paton. J. Neurobiol., 29 (1995), pp. 415-428

68. K.S. Cramer, C.I. Moore, M. Sur. J. Comp. Neurol., 353 (1995), pp. 306-316

69. W. Guido, et al. Visual Neurosci., 14 (1997), pp. 1167-1173

70. K.S. Cramer, et al. J. Neurosci., 16 (1996), pp. 7995-8004

71. A.E. Günlük, M.E. Bickford, S.M. Sherman. J. Comp. Neurol., 350 (1994), pp. 215-228

72. S. Kuchiiwa, et al. NeuroReport, 5 (1994), pp. 1662-1664

73. J.H. Sandell. J. Comp. Neurol., 251 (1986), pp. 388-397

74. H-J. Lúth, et al. J. Neurocytol., 23 (1994), pp. 770-782

75. J. Cudeiro, et al. J. Physiol., 504 (1997), pp. 467-478

76. P.R. Montague, et al. Science, 263 (1994), pp. 973-977

77. J.E. Dowling. The Retina. Harvard University Press (1987)

78. T.M. Dawson, et al. Proc. Natl. Acad. Sci. U. S. A., 88 (1991), pp. 7797-7801

79. B.T. Hope, et al. Proc. Natl. Acad. Sci. U. S. A., 88 (1991), pp. 2811-2814

80. D.I. Vaney, H.M. Young. Brain Res., 474 (1988), pp. 380-385

81. J.M. Provis, J. Mitrofanis. Vis. Neurosci., 4 (1990), pp. 619-623

82. G.N. Noll, et al. Neuropharmacology, 33 (1994), pp. 1407-1412

83. A. Savchenko, S. Barnes, R.H. Kramer. Nature, 390 (1997), pp. 694-698

84. Sherman, S.M. and Koch, C. (1988) in The Synaptic Organization of the Brain (Shepherd, G.M., ed.), pp 289-328, Oxford University Press

85. K.R. Hoyt, et al. Brain Res., 592 (1992), pp. 310-316

86. T. Akira, D. Henry, C.G. Wasterlain. Brain Res., 652 (1994), pp. 190-194

87. M.E. Bickford, et al. J. Comp. Neurol., 348 (1994), pp. 481-510

88. C. Iadecola. Trends Neurosci., 16 (1993), pp. 206-214

89. B.T. Hope, S.R. Vicent. J. Histochem. Cytochem., 37 (1989), pp. 653-661

90. C. Estrada, J. DeFelipe. Cereb. Cortex, 8 (1998), pp. 193-203

91. S.N.M. Reid, et al. J. Physiol., 494 (1996), pp. 511-517

92. E.S. Ruthazer, et al. J. Physiol., 494 (1996), pp. 519-527

93. F.O. Schmitt. Neuroscience, 13 (1984), pp. 991-1001

94. H.H.H.W. Schmidt, et al. Proc. Natl. Acad. Sci. U. S. A., 93 (1996), pp. 14492-14497

95. Feelisch, M. and Stamler, J.S. (1996) Methods in Nitric Oxide Research, pp. 19-28, John Wiley and Sons

96. A.J. Gow, D.D. Buerk, H. Ischiropoulos. J. Biol. Chem., 272 (1997), pp. 2841-2845

97. J.S. Stamler, D.J. Singel, J. Loscalzo. Science, 258 (1992), pp. 1898-1902

98. D.T. Hess, et al. Nature, 366 (1993), pp. 562-565

99. M.K. Meffert, et al. Neuron, 16 (1996), pp. 1229-1236

100. C.W. Mahoney, J.H. Pak, K-P. Huang. J. Biol. Chem., 271 (1996), pp. 28798-28804

101. H. Wolosker, et al. J. Neurochem., 66 (1996), pp. 1943-1948

102. M-C. Broillet, S. Firestein. Neuron, 16 (1996), pp. 377-385

103. T. Sato, et al. J. Neurochem., 68 (1997), pp. 1312-1318

104. E.M. Schuman, et al. Proc. Natl. Acad. Sci. U. S. A., 91 (1994), pp. 11958-11962 